\title{
Left Lung Bronchiole
}

National Cancer Institute

\section{Source}

National Cancer Institute. Left Lung Bronchiole. NCI Thesaurus. Code C49252.

A bronchiole located in the left lung. 